ORIGINAL ARTICLE

\title{
Complete Right Bundle Branch Block in Arrhythmogenic Cardiomyopathy: Similarities to Brugada Syndrome
}

\author{
Stefan Peters* \\ Department of Cardiology, MVZ Harz - Asklepios Harzklinik Goslar, Germany
}

*Corresponding author: Stefan Peters, Department of Cardiology, MVZ Harz - Asklepios Harzklinik Goslar, Asklepios Harzklinik Goslar, Kösliner Str. 12, 38642 Goslar, Germany

\begin{abstract}
Background: In arrhythmogenic cardiomyopathy complete right bundle branch block do appear. In rare cases complete right bundle branch block with Brugada-like presentation.

Method: In 24 patients with typical arrhythmogenic cardiomyopathy ECG showed complete right bundle branch block. In 17 cases atypical RBBB with low voltage were present, in 7 cases typical rSR' RBBB occurred.

Results: Brugada-like ECG could be excluded in 6 cases of typical complete rSR' right bundle branch block, only in one case Brugada ECG with coved-type ST segment elevation, sharp upstroke and symmetrical T-wave inversion was present.

Conclusion: In typical arrhythmogenic cardiomyopathy atypical low voltage and typical rSR' right bundle branch block appear. Only in one case with typical arrhythmogenic cardiomyopathy the ECG resembles classical Brugada ECG. In right bundle branch block both-arrhythmogenic cardiomyopathy and Brugada-like syndrome-could be presented as an overlap syndrome.
\end{abstract}

\section{Keywords}

Arrhythmogenic cardiomyopathy, Brugada syndrome, Complete right bundle branch block, Coved-type ST elevation

\section{Introduction}

Brugada syndrome is characterized by coved-type ST-segment elevation in one or two right precordial leads. Two types of coved-type ST elevation has been described: A form of complete right bundle branch block (about 60\%), in which right precordial leads demonstrate complete block and left precordial leads reveal nearly normal QRS configuration. In about $40 \%$ complete right bundle branch block with nearly identically increased QRS intervals.

In arrhythmogenic cardiomyopathy complete right bundle branch block occurs in 6 up to $40 \%$ of cases. The question is are there any similarities to the appearance of Brugada-like syndrome with coved-type ST elevation and negative $T$ waves in precordial leads.

\section{Method}

In a cohort of 433 patients ( 243 males with a mean age of 46.514 .8 years) the were 24 patients with complete right bundle branch block due to arrhythmogenic cardiomyopathy (6\%). The ECG's were analysed with regard to ST elevation and T-wave inversion in right precordial leads. Brugada-like ECG presents with sharp upstroke of the QRS complex to the S wave. Non-Bru-

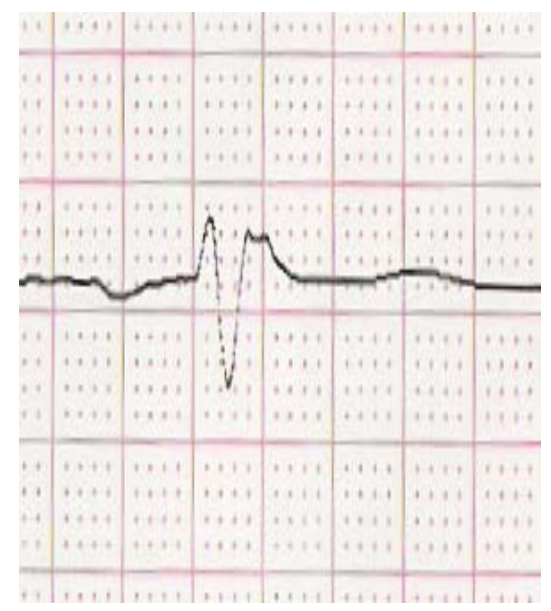

Figure 1: Atypical low voltage complete right bundle branch block in lead V1. 
gada ECG presents with smooth upstroke of the QRS complex.

\section{Results}

Among complete right bundle branch block there were 7 ECG's with typical rSR' complete right bundle branch block (Figure 1) and 17 ECG's with atypical complete low voltage right bundle branch block (Figure 2) possibly due to phospholamban founder mutation or advanced disease described in several papers [1,2].

In typical rSR' complete right bundle branch block one ECG resembles Brugada ECG, with coved-type ST elevation, sharp upstroke and symmetrical T-wave inversion (Figure 3). Only in very rare cases typical Brugada syndrome in lead V1 can be differentiated from typical complete right bundle branch block in lead V1 with rSR ' morphology and localized right precordial QRS prolongation (Figure 4).

\section{Conclusions}

The differentiation of Brugada-like ECG, typical rSR'

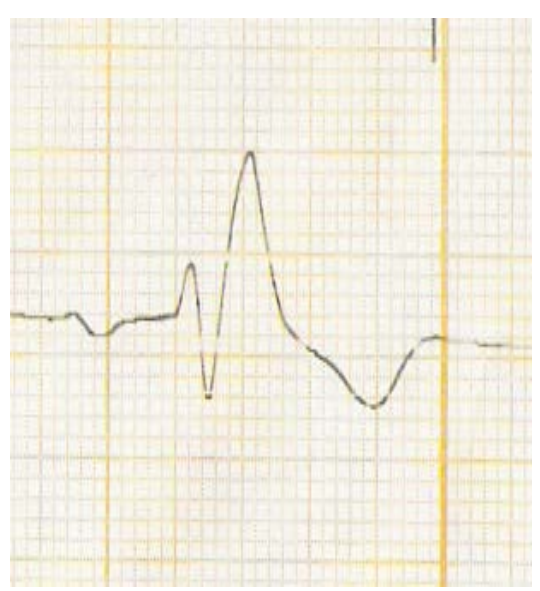

Figure 2: Typical rSR'complete right bundle branch block in lead $\mathrm{V} 1$.

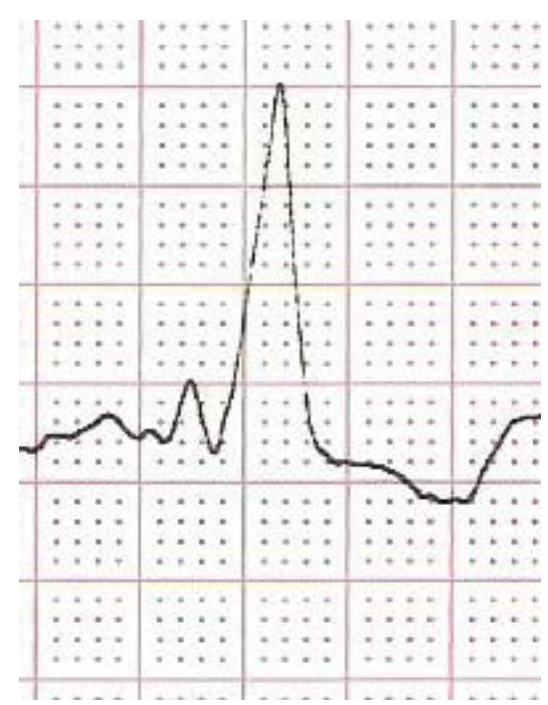

Figure 3: Brugada type I-like morphology of the QRS complex in lead V1 with coved-type ST elevation, sharp upstroke and symmetrical T-wave inversion. right bundle branch block and atypical low voltage right bundle branch block in arrhythmogenic cardiomyopathy is not easy to obtain.

In complete right bundle branch block it is forbidden to use ajmaline challenge to obtain Brugada ECG as a hint for the association of arrhythmogenic cardiomyopathy and Brugada syndrome. The paper of Calo, et al. [3] presented a modified figure of Oreto, et al. [4] transforming a patient of complete right bundle branch block with carotis sinus massage into a typical Brugada-like ECG.

In most cases early stage arrhythmogenic cardiomyopathy Brugada-like ECG can be provoked by ajmaline or flecainide challenge. These patients have a very high risk of developing ventricular fibrillation in the initial phase of predominant electrical disease. These are those patients who die as the first manifestation of the disease. Then they survive ventricular fibrillation, arrhythmogenic cardiomyopathy progress with the development of recurrent ventricular tachycardia in the follow-up.

In our case the patient was not an early stage of arrhythmogenic cardiomyopathy but an advanced form with severe right and left ventricular dilatation and functional reduction diagnosed by echocardiology and left and right ventricular angiography. But also in advances cases Brugada-like ECG can be presented [5].

In summary, careful analysis of complete right bundle branch block is important to make the diagnosis of arrhythmogenic cardiomyopathy and the association with Brugada syndrome as an overlap syndrome.

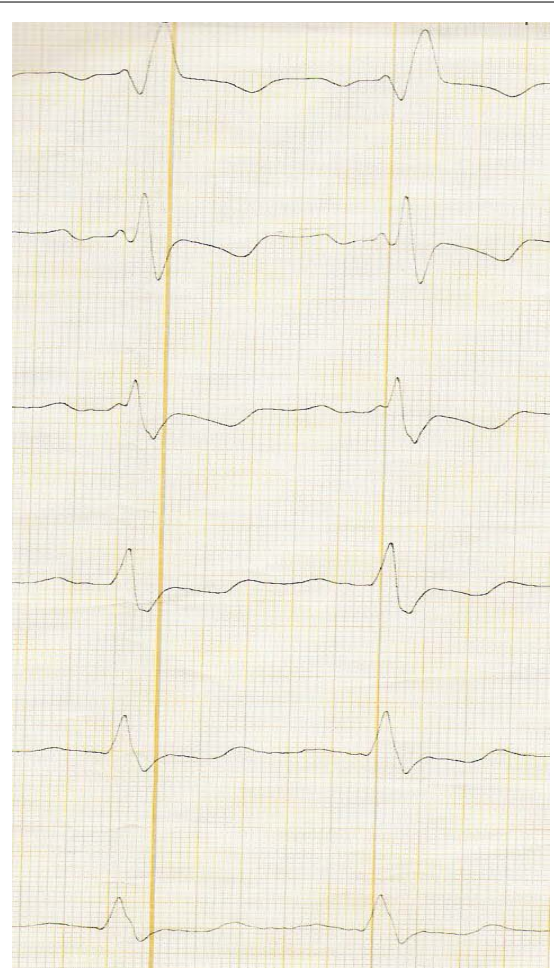

Figure 4: Typical complete right bundle branch block with localized right precordial QRS prolongation. 


\section{References}

1. Peters S, Trümmel M, Koehler B (2012) Special features of right bundle branch block in patients with arrhythmogenic right ventricular cardiomyopathy/dysplasia. Int J Cardiol 157: 102-103.

2. Peters, S (2018) Electrocardiographic criteria in founder mutations related to arrhythmogenic cardiomyopathy. J Cardiol Cardiovasc Med 3: 005-007.

3. Calo L, Martino AE, Okumura Y, de Ruvo E (2018) Right bundle branch block and conduction disturbances in
Brugada syndrome and arrhythmogenic right ventricular cardiomyopathy. J Interv Card Electrophysiol 52: 307-313.

4. Oreto G, Corrado D, Delise P, Fedele F, Gaita F, et al. (2010) Doubts of the cardiologist regarding an electrocardiogram presenting QRS V1-V2 complexes with positive terminal wave and ST segment elevation. Consensus Conference promoted by the Italian Cardiology Society. G Ital Cardiol 11: $3 S-22 S$

5. Peters S (2016) Early and late manifestion of Brugada syndrome ECG in arrhythmogenic cardiomyopathy. Int J Cardiol 220: 260-261. 